\title{
An illustration of the explanatory and discovery functions of proof
}

\begin{abstract}
Author:
Michael de Villiers ${ }^{1}$

Affiliation:

${ }^{1}$ Mathematics Education, University of KwaZulu-Natal, Edgewood Campus,

South Africa

Correspondence to:

Michael de Villiers

Email:

profmd@mweb.co.za

Postal address:

Private Bag X03, Ashwood

3605, South Africa

Dates:

Received: 15 Aug. 2012

Accepted: 27 Sept. 2012

Published: 30 Nov. 2012

How to cite this article: De Villiers, M. (2012). An illustration of the explanatory and discovery functions of proof. Pythagoras, 33(3), Art. \#193, 8 pages. http://dx.doi. org/10.4102/pythagoras. v33i3.193

\section{Note:}

This article is based on a presentation at the 12 th International Congress on Mathematical Education, July 2012, COEX, Seoul, Korea. Workshops on Clough's conjecture have also been conducted at the NCTM Annual Meeting, April 2004, Philadelphia, USA, as well as at the AMESA Congress, July 2004, North-West University, Potchefstroom, South Africa (De Villiers, 2004).
\end{abstract}

C 2012. The Authors. Licensee: AOSIS OpenJournals. This work is licensed under the Creative Commons Attribution License.
This article provides an illustration of the explanatory and discovery functions of proof with an original geometric conjecture made by a Grade 11 student. After logically explaining (proving) the result geometrically and algebraically, the result is generalised to other polygons by further reflection on the proof(s). Different proofs are given, each giving different insights that lead to further generalisations. The underlying heuristic reasoning is carefully described in order to provide an exemplar for designing learning trajectories to engage students with these functions of proof.

\section{Introduction}

It seems that the human brain is designed, or has evolved over time, not only to recognise patterns, but also often to impose them on things we observe. Moreover, from a very young age, children naturally exhibit a need for an explanation of these patterns - a deep-seated curiosity about how or why things work the way they do. They ask questions about why the sky is blue, the sun rises in the East, or why more moss grows on the southern side of a tree (in the Southern Hemisphere).

However, it sadly seems that once young children have entered the domain of mathematics in formal schooling, this natural inquisitiveness and quest for deeper understanding becomes severely repressed. Largely to blame is probably the traditional approach of focusing primarily on the teaching, learning and practising of standard algorithms. These are still presented in many classrooms as mystical chants to be memorised, rather than focusing on understanding why they work, as well as on the meaning of the basic operations underlying them. Lockhart (2002) laments this sorry state of affairs:

By concentrating on what, and leaving out why, mathematics is reduced to an empty shell. The art is not in the 'truth' but in the explanation, the argument. It is the argument itself which gives the truth its context, and determines what is really being said and meant. Mathematics is the art of explanation. If you deny students the opportunity to engage in this activity - to pose their own problems, make their own conjectures and discoveries, to be wrong, to be creatively frustrated, to have an inspiration, and to cobble together their own explanations and proofs - you deny them mathematics itself. (p. 5, [emphasis in the original])

\section{Extending the role of proof beyond verification}

Traditionally, the verification (justification or conviction) of the validity of conjectures has been seen as virtually the only function or purpose of proof. Most mathematics teachers probably see this as the main role of proof (Knuth, 2002) and this view, to the exclusion of a broader perspective, also still dominates much of curriculum design in the form of textbooks, lessons and material on teaching proof (French \& Stripp, 2005). Even the majority of research conducted in the area of proof has been done from this perspective (Balacheff, 1988; Ball \& Bass, 2003; Harel \& Sowder, 2007; Stylianides \& Ball, 2008). Harel and Sowder, for example, defines a 'proof scheme' as an argument that 'eliminates doubt', effectively restricting the role of reasoning and proof to only that of verification, although they acknowledge the explanatory role of proof in other places.

In the past few decades, however, this narrow view of proof has been criticised by several authors (e.g. Bell, 1976; De Villiers, 1990, 1998; Hanna, 2000; Thurston, 1994; Rav, 1999; Reid, 2002, 2011). They have suggested that other functions of proof such as explanation, discovery, systematisation, intellectual challenge et cetera, have in some situations been of greater importance to mathematicians and can have important pedagogical value in the mathematics classroom as well. But these distinctions of other roles for proof are perhaps far older. For example, Arnauld and Nicole (1662) appear to be referring to the explanatory (illuminating or enlightening) role of proof by objecting to Euclid because they felt Euclid was 'more concerned with convincing the mind than with enlightenment' (cited by Barbin, 2010, p. 237). 


\section{Computing technology and the changing role of proof}

Mejía-Ramos (2002, p. 6) argues that the search for deeper understanding is what makes many mathematicians reject 'mechanically-checked formal proofs and computational experiments as mathematical proofs', for example, the famous use of computers by Appel and Haken in 1976 to prove the four-colour conjecture (Appel \& Haken, 1977). Especially in the light of modern computing technology, such as dynamic geometry and symbolic algebraic processors, it is often the case that a very high level of conviction is already obtained before mathematicians embark on finding a proof. In fact, it can be argued that this 'a priori' conviction is more often a prerequisite and motivating factor (Polya, 1954, pp. 83-84) for looking for a proof than the mythical view that 'eliminating doubt' is the driving force.

On the other hand, although such computing tools enable us to gain conviction through visualisation or empirical measurement, these generally provide no satisfactory insight into why the conjecture may be true. It merely confirms that it is true, and although considering more and more examples may increase our confidence to a greater extent, it gives no psychologically satisfactory sense of illumination (Bell, 1976) or enlightenment - for that, some form of proof is needed! In this regard, it is significant to note that young Grade 9 children still display a need for some form of further explanation (deeper understanding) of a result, which they had already become fully convinced of after empirical exploration on Sketchpad (Mudaly \& De Villiers, 2000). Within the context of algebra, Healy and Hoyles (2000) also found that students preferred arguments that both convinced and explained, strongly suggesting that the need for explanation is perhaps an untapped resource in lesson design and implementation.

Appreciation of the verification (justification) function of proof is most easily developed in fields such as number theory, algebra, calculus, et cetera. In these fields one can give spectacular counter-examples to conjectures with massive empirical support (e.g. as in Stylianides, 2011). However, this is not quite the case with dynamic geometry. The difference is that one can transform geometric figures or graphs continuously (or at least closely) by dragging, as well as explore more deeply by zooming in to great levels of accuracy. With these facilities, one can usually find counter-examples to false conjectures fairly quickly and easily. It is possible to contrive didactical situations such as used in De Villiers $(2003$, pp. 73,85$)$ where students are given sketches with measurements preset to one decimal accuracy, therefore deliberately misleading them to make a false conjecture. However, genuinely authentic examples in dynamic geometry that are accessible to high school students are few and far between.

It seems more natural and meaningful that within a dynamic geometry (mathematics) environment, potential use may be made of this cognitive need for explanation and understanding to design and implement alternative learning activities. Such learning activities could introduce novices for the first time to proof, not as a means of verification, but as a means of explanation and illumination (e.g. see De Villiers,
1998, 2003), whilst the other functions of proof could be developed later or in other contexts. Furthermore, by initially referring to a deductive argument as a 'logical explanation' instead of a 'proof, it may help to focus attention on its role as a means of deeper understanding of a dynamically verified result rather than of conviction or verification.

\section{Proof as a means of discovery}

Quite often, logically explaining (proving) why a result is true gives one deeper insight into its premises. On further reflection, one may then realise that it can be generalised or applied in other circumstances. Anderson (1996, p. 34) also clearly alludes to this aspect when writing, 'Proof can bring understanding of why methods work and, consequently, of how these methods might be adapted to cope with new or altered circumstances.' Rav (1999, p. 10) also describes this 'productive' role of proof when writing: ' ... logical inferences are definitely productive in extending knowledge by virtue of bringing to light otherwise unsuspected connections.' More recently, Byers (2007, p. 337) has made a similar observation: 'A "good" proof, one that brings out clearly the reason why the result is valid, can often lead to a whole chain of subsequent mathematical exploration and generalization.'

I have called this illuminating aspect of proof that often allows further generalisation, the discovery function (De Villiers, 1990), and it appears also to be the first explicit distinction of this function (Reid, 2011). For example, explaining (proving) Viviani's theorem for an equilateral triangle by determining the area of the three triangles it is divided up into, and noticing the 'common factor' of the equal sides of these triangles as bases, may allow one to immediately see that the result generalises to any equilateral polygon, because exactly the same 'common factor' will appear (De Villiers, 2003, p. 26).

Nunokawa (2010, pp. 231-232) similarly claims that 'explanations generate new objects of thought to be explored'. He gives an example of a problem involving two overlapping squares, and how explaining why the overlapping area remains constant as the one square remains fixed and the other is rotated, leads one to generalise to other regular polygons with the same feature. Two other 'discovery via proof' examples are discussed and presented in De Villiers (2007a, 2007b). Of course, for novices and less experienced students such generalisation (or specialisation) from a proof is not likely to be as automatic and immediate as with an experienced mathematician. Therefore, in didactically designing tasks to engage high school students, or even student teachers, with the discovery function of proof, sufficient scaffolding is often needed to provide adequate guidance for both the initial proof as well as for further reflection (Hemmi \& Löfwall, 2011; Miyazaki, 2000).

Jones and Herbst (2012, p. 267) reporting on a study on the instructional practices of a sample of expert teachers of geometry at Grade 8 level (pupils aged 13-14) in Shanghai, China, identify two important factors in developing an understanding of the discovery function of proof, namely, 
variation of the mathematical problems as well as the questions asked by teachers to guide their students.

It is important to also point out here that with the 'discovery' function of proof is not only meant a discovery made after reflecting on a recently constructed proof. As illustrated in De Villiers (1990, p. 22, 2003, pp. 68-69), it also more broadly refers to situations where new results are discovered in a purely logical way by the application of known theorems or algorithms without resorting to any experimentation, construction or measurement. For example, using the tangents to a circle theorem, it is relatively easy to deduce logically (and proving at the same time) that the two sums of the opposite sides of a quadrilateral circumscribed around a circle are equal (and generalising to circumscribed $2 n$-gons).

Another illustrative example is given in De Villiers (1999) involving the generalisation of a problem involving an area relationship between a square and a formed octagon. By dividing the sides into different ratios than the original, it was experimentally found with dynamic geometry that the area ratios remained constant. However, a purely inductive approach whereby the different ratios $0.1666 ; 0.3333 ; 0.4500$ were looked at for the division of the sides into halves, thirds and quarters respectively, was not very helpful in finding a general formula and ultimately had to be derived logically.

More generally, with the discovery function, it also means that a proof can reveal new, powerful methods of solving problems and creating new theories. Logical reasoning and proof can show that certain problems are unsolvable such as, for example, representing $\sqrt{2}$ as a rational (fraction), squaring the circle or solving a quintic (or higher order) polynomial equation with radicals. Hanna and Barbeau (2010, pp. 90-93) suggest a nice example for classroom use, showing how the problem of finding the quadratic formula naturally leads to an introduction to students of the strategy of completing the square. Grabiner (2012, p. 161) gives historical examples of how the distinction between pointwise and uniform convergence arose from counter-examples to Cauchy's supposed theorem regarding infinite series, and of how Cantor's theory of the infinite came about through trying to specify the structure of the sets of real numbers on which Fourier series converge. Similarly, the discovery (invention) of non-Euclidean geometry came about from attempts to use indirect proof (reductio ad absurdum) to prove Euclid's 5th postulate. Grabiner (2012, p. 162) describes this as 'another triumph of human reason and logic over intuition and experience'.

The main purpose of this article is to contribute further to the theoretical aspects of the role of proof by providing a heuristic description of some of my personal experiences of the explanatory and discovery functions of proof with a geometric conjecture made by a Grade 11 student. After logically explaining (proving) the result geometrically and algebraically, the result is generalised to other polygons by further reflection on the proof(s). This conjecture and its generalisations could easily be turned into a set of guided learning activities that elicit 'surprise' amongst students (compare Movshovitz-Hadar, 1988); therefore creating a need for explanation, and provide an authentic mix of experimentation and proof of a possibly original result.

\section{Clough's conjecture}

Although it is a rare occurrence, nothing gives greater pleasure to a teacher than when one of their students produces a conjecture of their own. The conjecture need not be entirely original, but the excitement created in the classroom when something goes 'outside' or 'beyond' the textbook gives a much more 'real' sense of genuine mathematical discovery and invention. Usually, students are also far more strongly motivated to want to solve such a problem because they perceive it as their own and not something old and boring from the textbook or the curriculum.

By encouraging students, for example, to continually ask 'what-if' questions on their own until it becomes a regular occurrence, students are likely to more naturally start making more original conjectures of their own, providing an exciting injection to liven up the class. The availability of computing technology places at the disposal of students powerful new tools by which they can now easily make independent discoveries (Arzarello, Bartolini Bussi, Leung, Mariotti \& Stevenson, 2012; Borwein, 2012). A useful overview and analysis for the task-design of activities for promoting conjecturing is given by Lin, Yang, Lee, Tabach and Stylianides (2012). Moreover, speaking from my own experience also, honouring students by attaching their names to discovered results is a powerful motivator to continue further mathematical studies (compare Leikin, 2011).

During 2003, a Grade 11 student from a high school in Cape Town was exploring Viviani's theorem using dynamic geometry. The theorem says that the sum of distances of a point to the sides of an equilateral triangle is constant (i.e. in Figure $1 P P_{a}+P P_{b}+P P_{c}$ is constant, irrespective of the position of point $P$ inside triangle $A B C$ ). The student's further exploration led him to measure the distances $A P_{c^{\prime}} B P_{a}$ and $C P_{b}$, and then add them. To his surprise, he noticed that $A P_{c}+B P_{a}+C P_{b}$ also remained constant no matter how much he dragged $P$ inside the triangle. However, he could not prove it.

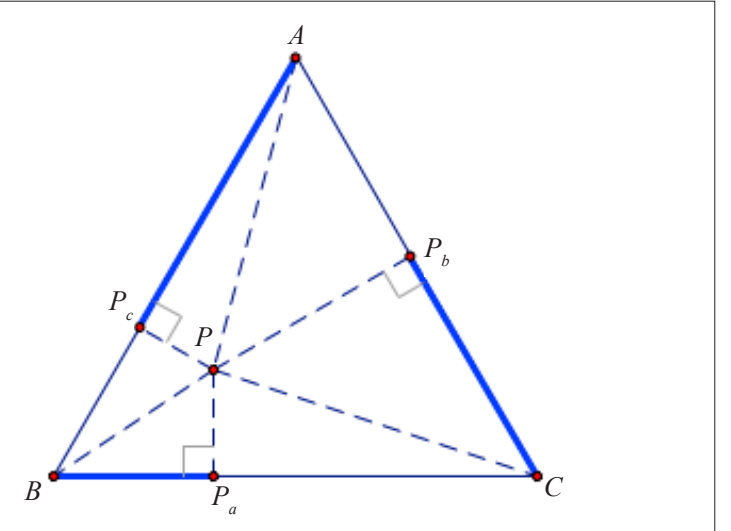

FIGURE 1: Clough's conjecture: $A P_{c}+B P_{a}+C P_{b}$ is constant. 
His teacher eventually wrote to me to ask whether I could perhaps produce a simple geometric proof, as he himself could only prove it algebraically by means of co-ordinate geometry. Below is the geometric proof I first produced, followed by further proofs, explorations and different generalisations of what has become known as Clough's conjecture (De Villiers, 2004).

\section{Geometric proof}

Problem solving heuristics are valuable in that they often direct the problem solver towards a successful solution of a problem. George Polya (1945) gives the following useful examples:

Have you seen it before? Or have you seen the same problem in a slightly different form? Do you know a related problem? Do you know a theorem that could be useful? Look at the unknown! And try to think of a familiar problem having the same or a similar unknown. Here is a problem related to yours and solved before. Could you use it? Could you use its result? Could you use its method? Should you introduce some auxiliary element in order to make its use possible? (p. xvii)

Following Polya's heuristic, it seems natural to try and relate Clough's conjecture to Viviani's theorem and its proof. After several different attempts, I found by constructing perpendiculars to $A B, B C$ and $C A$ as 'auxiliary elements' respectively at $A, B$ and $C$, that I obtained a triangle $K L M$ as shown in Figure 2.

Considering that $\angle A B K=30^{\circ}$, it follows that $\angle A K B=60^{\circ}$. In the same way the other angles of $\triangle K L M$ can be shown to be equal to $60^{\circ}$; hence $\triangle K L M$ is equilateral.

Next, drop perpendiculars from $P$ to sides $K M, K L$ and $L M$ respectively. It then follows that quadrilateral $A P_{c} P A^{\prime}$ is a

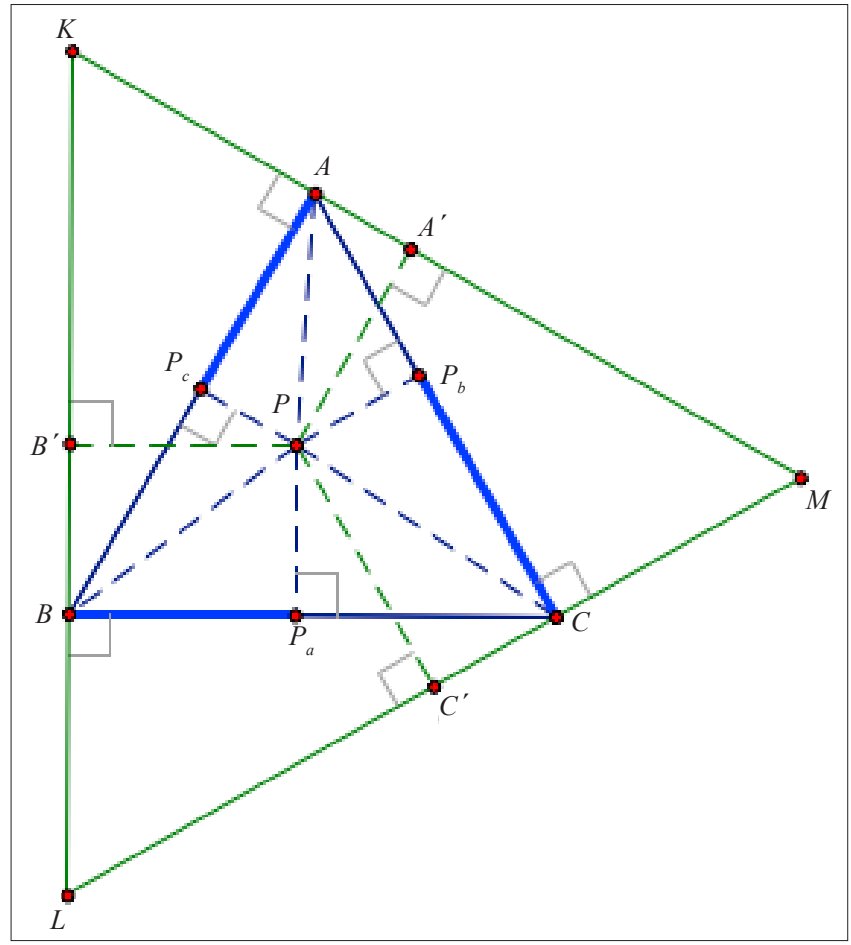

FIGURE 2: A geometric proof of Clough's conjecture. rectangle because all its angles are right angles. Therefore, $A^{\prime} P=A P_{c^{\prime}}$ and similarly, $B^{\prime} P=B P_{a}$ and $C^{\prime} P=C P_{b}$.

Clearly the problem is now reduced to Viviani's theorem in relation to $\triangle K L M$. Considering that $A^{\prime} P+B^{\prime} P+C^{\prime} P$ is constant, it follows that $A P_{c}+B P_{a}+C P_{b}$ is also constant. QED.

The preceding proof is quite explanatory (Hanna, 1989) as one can almost immediately 'visually see' from the diagram in one 'gestalt', why the result is true and how it relates to Viviani's theorem.

\section{An alternative 'algebraic' proof}

In Polya's final step of problem-solving, namely, looking back, he asks amongst other things whether one can derive or prove the result differently. In doing so, not only is one developing a variety of problem-solving (proving) skills, but one may also gain additional insight into the result. Recently, much has been written and researched about the value of posing such multi-proof tasks to students. Dreyfus, Nardi and Leikin (2012) provide a comprehensive survey and review of this particular field.

Considering that there are several right triangles, it seems reasonable to try the theorem of Pythagoras, and to apply it to each of these triangles and investigate where it leads.

Let $A B=a, A P_{C}=x$, et cetera, as shown in Figure 3. We now need to show that $x+y+z$ is constant. Applying Pythagoras to the right triangles adjacent to the hypotenuses $A P, B P$ and $C P$, we obtain:

$$
\begin{aligned}
& x^{2}+P P_{c}^{2}=(a-z)^{2}+P P_{b}^{2} \\
& y^{2}+P P_{a}^{2}=(a-x)^{2}+P P_{c}^{2} \\
& z^{2}+P P_{b}^{2}=(a-y)^{2}+P P_{a}^{2}
\end{aligned}
$$

It is often at this point, or even before reaching it, that a novice problem solver might lose hope of getting anywhere as it is not obvious from the start that this will lead somewhere useful. However, students should be encouraged to persist with such an exploration and not so easily give up and start asking for help. One might say that a distinctive characteristic of good mathematical problem solvers are that they are 'stubborn', and willing to spend a long time attacking a problem from

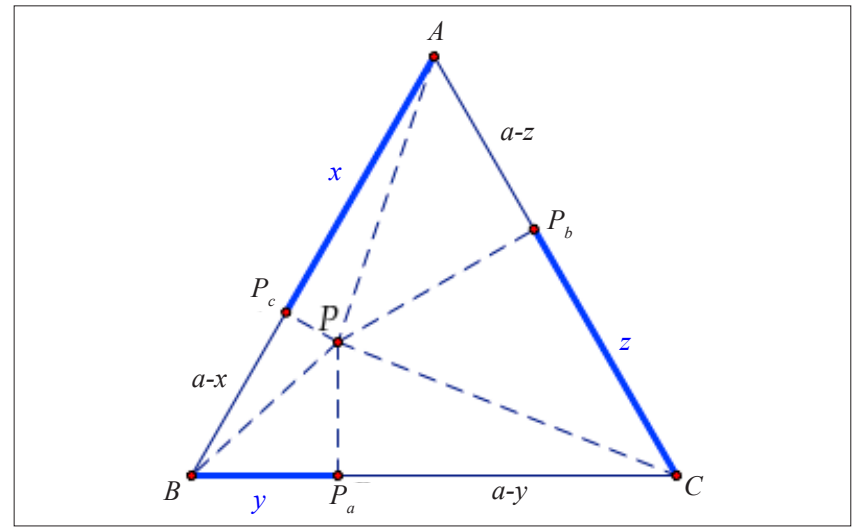

FIGURE 3: An alternative, algebraic proof of Clough's conjecture. 
different vantage points and not easily surrendering. In this regard, Schoenfeld (1987, p. 190-191) also specifically refers to the importance of meta-cognition during problemsolving (i.e. maintaining a conscious awareness and control of a variety of possible approaches, and then monitoring how well things are going during the implementation of a possible approach).

If we look at the set of three equations, however, an immediate observation is the cyclic fashion in which terms appear. This suggests that adding the left and right sides of the three equations, respectively, might lead to the quadratic terms cancelling out. Indeed, doing so, after simplification, gives us the desired identity $x+y+z=\frac{3}{2} a$. Considering that $a$ is constant for a fixed equilateral triangle, it completes the proof.

Taking into account that $\frac{3}{2} a$ is half the perimeter of the triangle, we also get the following bonus relationship: $A P_{c}+B P_{a}+C P_{b}=P_{c} B+P_{a} C+P_{b} A$.

Although this algebraic proof appears less explanatory than the preceding geometric one, we have managed to find an additional property of the configuration that was not discovered experimentally, namely, that the sum of these distances is half the perimeter of the triangle. Nor was this clearly evident from the geometric proof at all, although one could now go back armed with this hindsight and use basic trigonometric ratios in Figure 2 to find that the side length of $\triangle K L M$ is $\sqrt{3} a$; hence its height is $\frac{3}{2} a$ (which is equal to its Viviani sum).

However, more importantly, because of its cyclic nature, the algebraic proof suggests an immediate generalisation to equilateral polygons, giving a nice illustrative example of the discovery function of proof. It is not hard to see (at least for more experienced problem solvers) that from the structure of the proof, it will generalise as follows for an equilateral $n$-gon $A_{1} A_{2} \ldots A_{n}$ (refer to the notation in Figure 4, showing an equilateral pentagon):

$$
\begin{aligned}
& x_{1}^{2}+P P_{1}^{2}=\left(a-x_{n}\right)^{2}+P P_{n}^{2} \\
& x_{2}^{2}+P P_{2}^{2}=\left(a-x_{1}\right)^{2}+P P_{1}^{2} \\
& \cdots \\
& x_{n-1}^{2}+P P_{n-1}^{2}=\left(a-x_{n-2}\right)^{2}+P P_{n-2}^{2} \\
& x_{n}^{2}+P P_{n}^{2}=\left(a-x_{n-1}\right)^{2}+P P_{n-1}^{2}
\end{aligned}
$$

By again adding the left and the right sides as before, we get a collapsing 'telescopic effect' with all the squares of $P P_{n}$ and $x_{i}$ cancelling out, and all that remains is $0=n a^{2}-2 a\left(x_{1}+x_{2}+\ldots+x_{n}\right)$ which simplifies to $\sum x_{i}=\frac{n}{2} a$, which as before, is also half the perimeter of the equilateral n-gon.

\section{Revisiting the geometric proof}

Let us now revisit our explanatory geometric proof. Despite already knowing that Clough's result is true for a rhombus (as it has all its sides equal), let us nonetheless see if we can use the same geometric approach with it as for the triangle, and whether it provides any new insights. By constructing perpendiculars as before to $A D, D C, C B$ and $B A$ respectively at $A, D, C$ and $B$ as shown in Figure 5, we find that the result is visually immediately obvious. For example, perpendiculars $a$ and $c$ are parallel to each other because they are respectively perpendicular to sides $A D$ and $B C$. Because it is easy to show that $F P H$ is a straight line, we see that $A H+C F$ is simply equal to the constant distance between these two parallel lines. The same applies to the sum of the other two distances $B E$ and $D G$ between the parallel perpendiculars $b$ and $d$. Therefore, $A H+C F+B E+D G$ is the sum of two constants; hence constant. QED.

In many ways this proof is more explanatory than the preceding algebraic proof, which was more algorithmic, nonvisual and required quite a bit of manipulation. Moreover, following Polya, and looking back critically and examining this geometric proof, one should notice that we did not use the equality of the sides of the rhombus at all! We only used its property of opposite sides being parallel - it depends only on the parallel-ness of opposite sides. This implies that the result will immediately not only generalise to a parallelogram, but also in general to any parallel $2 n$-gon $(n>1)$; in other words to any even sided polygon with opposite sides parallel, as the same argument will apply!

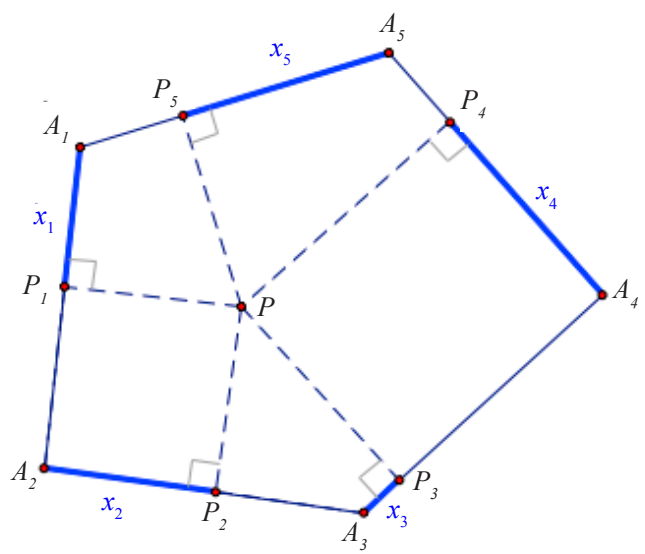

FIGURE 4: An equilateral pentagon.

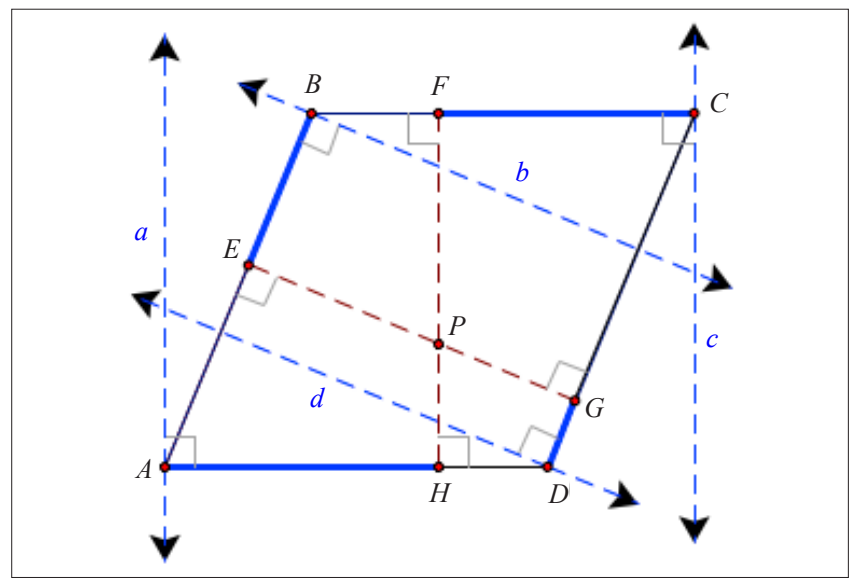

FIGURE 5: A geometric proof for a rhombus. 
So here we have another excellent example of the discovery function of proof, leading us to a further generalisation, without any additional experimentation. As shown in Figure 6 for a hexagon with opposite sides parallel, exactly the same argument applies to the sum of the distances $A H$ and $D K$ respectively on opposite parallel sides, and lying between the two parallel perpendiculars $a$ and $d$, et cetera.

\section{Generalising to equi-angled polygons}

Given that Viviani's theorem generalises not only to equilateral polygons and $2 n$-gons with opposite sides parallel, but also to equi-angled polygons, it seemed reasonable to investigate whether Clough's theorem is also true for polygons of this kind. Considering that it is true for parallelograms, it is true for the quadrilateral case (a rectangle), but what about an equi-angled pentagon?

A quick construction on Sketchpad showed me that the result was indeed also true for an equi-angled pentagon. Although I personally had no doubt about the equi-angled result from this experimental investigation, I was nonetheless motivated to look for a proof, because I wanted to know why it was true, as well as seeing it as an intellectual challenge (compare with Hofstadter, 1997, p. 10). It was therefore not about the 'removal of doubt' for me at all!

Once again, one can try the same strategy used before by constructing perpendiculars at the vertices and attempt to relate it to something we already know, namely Viviani's generalisation to equi-angled polygons.

Given that $A B C D E$ is a pentagon with equal angles as shown in Figure 7, draw perpendiculars to each side at the vertices $A$ to $E$, and label as $K$ the intersection of the perpendicular from $A$ with that of the perpendicular from $E$. Similarly, as shown, label the other intersections of the perpendiculars as $L, M, N$ and $O$. From $Q$ draw perpendiculars $Q J$ to $A E$ and $Q X$ to $E K$ (extended) to obtain rectangle $E J Q X$. Therefore, $Q X=E J$.

In the same way, construct rectangles to replace the other four segments $A F, B G, C H$ and $D I$ with the corresponding perpendiculars from $Q$ to the sides of $K L M N O$ as shown. Now note that $\angle E A B=90^{\circ}+\angle E A K$, but $\angle O K L=90^{\circ}+\angle E A K$, because $\angle O K L$ is the exterior angle of $\triangle E A K$. Hence, $\angle O K L=\angle E A B$.

Similarly, it can be shown that the other angles of the inner pentagon are correspondingly equal to that of the outer one; hence that $K L M N O$ is also an equi-angled pentagon. But we know that the sum of the distances from a point to the sides of any equi-angled polygon is constant, and because all these five distances are correspondingly equal to the distances $E J, A F, B G, C H$ and $D I$ by construction, the required result follows. QED.

Looking back at this proof, we can also see that we did not use the angle size $\left(108^{\circ}\right)$ specific to the equi-angled pentagon to show that $\angle O K L=\angle E A B$. This immediately implies that for any polygon with equal angles the same construction would produce another equi-angled polygon inside! Hence, the result generalises, and we have here another lovely example of the discovery function of proof.

Another perhaps even easier way of logically explaining the theorem is shown in Figure 8. By translating the segments $B G, C H, D I$ and $E J$ as shown, and then constructing perpendiculars at $A, B^{\prime}, C^{\prime}, D^{\prime}$ and $E^{\prime}$, we produce another

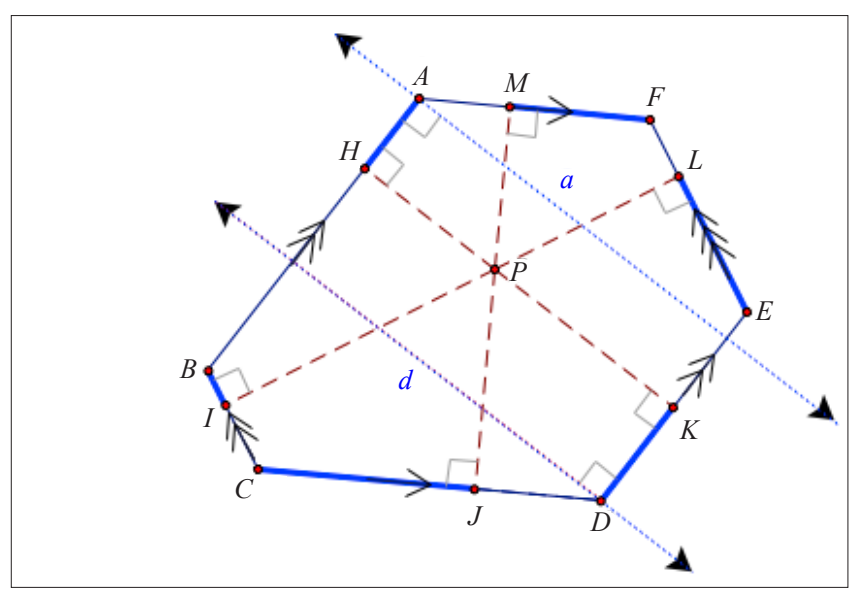

FIGURE 6: A hexagon with opposite sides parallel.

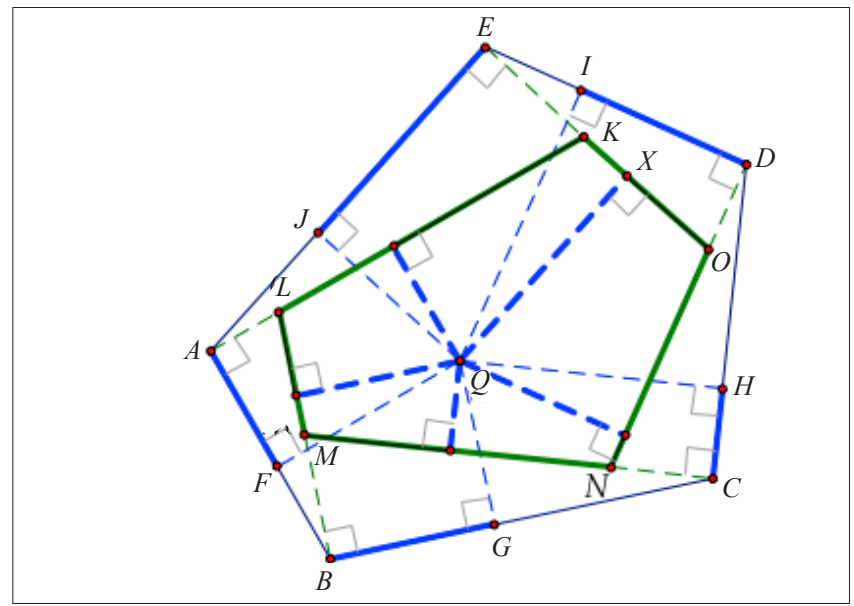

FIGURE 7: An explanatory proof for an equi-angled pentagon.

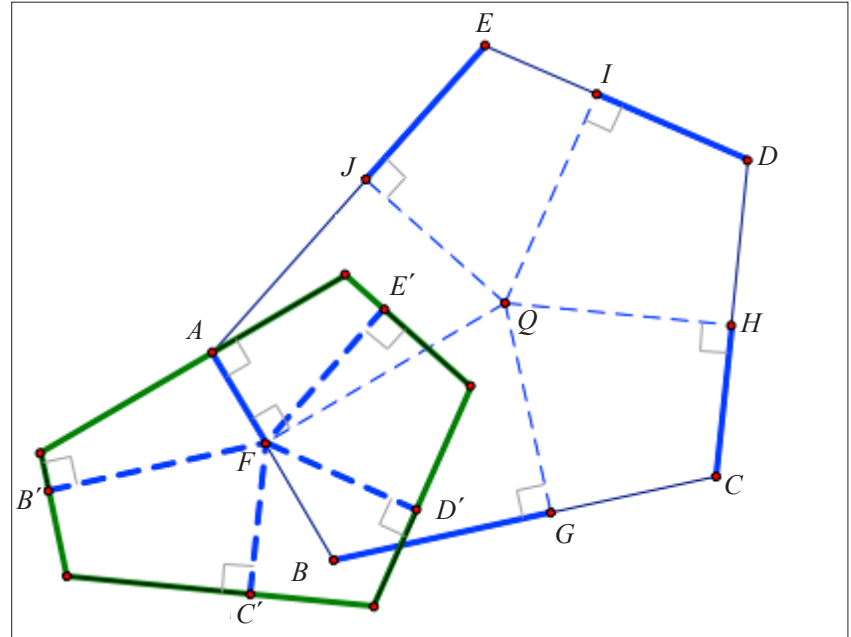

FIGURE 8: An alternative explanation (proof) for an equi-angled pentagon. 
equi-angled pentagon (left to the reader to prove) and the result follows as before.

\section{Concluding comments}

Although it is probably not feasible to attempt to introduce complete novices to the 'looking back' discovery function of proof with the specific examples illustrated here, I believe it is possible to design learning activities for younger students in the junior secondary school and even in the primary school. This could at least acquaint students with the idea that a deductive argument can provide additional insight and some form of novel discovery.

For example, De Villiers (1993) shows that to algebraically explain why the sum of a two-digit number and its reverse is always divisible by 11 can lead students to see that the other factor is the sum of the digits of the original number, which they may not have noticed from considering only a few cases. This activity has been done many times with both high school students as well as pre-service and in-service teachers. It has been very seldom that any of them noticed this additional property in the empirical phase, and they would express appreciative surprise at finding this out later from the proof when their attention was directed towards it.

Instead of defining proof in terms of its verification function (or any other function for that matter), it is suggested that proof should rather be defined simply as a deductive or logical argument that shows how a particular result can be derived from other proven or assumed results; nothing more, nothing less. It is not here suggested that fidelity to the verification function of proof is sacrificed at all, but that it should not be elevated to a defining characteristic of proof. Moreover, the verification function ought to be supplemented with other important functions of proof using genuine mathematical activities as described above. It is also not suggested that the preceding examples be directly implemented in a classroom as their success will depend largely on the past experience, expertise and ability of the audience, the classroom culture, as well as the skill of the teacher as a facilitator of learning. For example, Zack (1997, p. 1) contends that in her fifth grade classroom 'for an argument to be considered a proof, the students need not only convince, but also to explain'. She then proceeds to give an example of how this broader 'didactical contract' with respect to proof motivated her students to actively engage in conjecturing, refuting and eventually developing a proof as a logical explanation through her continued insistence that they demonstrate why the pattern worked.

Leong, Toh, Tay, Quek and Dindyal (2012) similarly describe some success using a worksheet based on Polya's model to guide a high achieving student to 'look back' at his solution and push him to further extend, adapt and generalise his solution. One could speculate, and it might be an interesting longitudinal study, that students who've been exposed to several such activities are more likely to spontaneously start 'looking back' at their solutions to problems and start considering generalisations or pose new questions. Problem posing and generalisation through the utilisation of the 'discovery' function of proof is as important and creative as problem-solving itself, and ways of encouraging this kind of thinking in students need to be further explored.

Johnston-Wilder and Mason (2005, p. 93) and Mason, Burton and Stacey (1982, p. 9) have claimed that generalisation lies at the 'heart' of mathematics and is its 'life-blood', and give many instructive examples. It certainly is an important mathematical activity that students need to engage in far more than is perhaps currently the case in classroom practice. It is important to broadly distinguish between two kinds of generalisation, namely, inductive and deductive generalisation. With inductive generalisation is meant the generalisation from a number of specific cases by empirical induction or analogy, and is usually the meaning given to the word 'generalisation' in the literature. With deductive generalisation is meant the logical reflection (looking back on) and consequent generalisation of a critical idea to more general or different cases by means of deductive reasoning. In other words, generalising the essence of a deductive argument and applying it to more general or analogous cases. Three examples of this deductive kind of generalisation have been illustrated in this article.

Schopenhauer (as quoted by Polya, 1954) aptly describes the educational value of the process of further generalisation to assist in the integration and synthesis of students' knowledge as follows:

Proper understanding is, finally, a grasping of relations (un saisir de rapports). But we understand a relation more distinctly and more purely when we recognize it as the same in widely different cases and between completely heterogeneous objects. (p. 30)

In terms of learning theory, the process of generalisation corresponds to some extent to 'superordinate learning' as distinguished by Ausubel, Novak and Hanesian (1978, p. 68), where an inclusive idea or concept is generalised or abstracted, under which already established ideas can be meaningfully subsumed.

Finally, it is hoped that this article will stimulate some more design experiments in problem solving as suggested by Schoenfeld (2007), focussing not only on developing appreciation of the explanatory and discovery functions of proof, but also on other functions of proof such as systematisation, communication, intellectual challenge, et cetera. The aim is that ultimately, school curricula, textbooks and teachers can begin to present a more comprehensive, realistic and meaningful view of proof to students.

\section{Acknowledgements Competing interests}

I declare that I have no financial or personal relationships, which may have inappropriately influenced me in writing this article. 


\section{References}

Anderson, J. (1996). The place of proof in school mathematics. Mathematics Teaching 155, 33-39.

Appel, K., \& Haken, W. (1977). Solution of the four color map problem. Scientific American, 237(4), 108-121. http://dx.doi.org/10.1038/ scientificamerican1077-108

Arzarello, F., Bartolini Bussi, M.G., Leung, A.Y.L., Mariotti, M.A., \& Stevenson, I. (2012) Experimental approaches to theoretical thinking: Artefacts and proofs. In G. Hanna, \& M. de Villiers (Eds.), Proof and proving in mathematics education (pp. 97-143). Dordrecht: Springer.

Ausubel, D.P., Novak, D., \& Hanesian, H. (1978). Educational Psychology: A cognitive view. New York, NY: Holt, Rinehart \& Winston.

Balacheff, N. (1998). Aspects of proof in pupils' practice of school mathematics. In D. Pimm (Ed.), Mathematics, teachers and children (pp. 216-235). London: Hodder \& Stoughton.

Ball, D.L., \& Bass, H. (2003). Making mathematics reasonable in school. In J. Kilpatrick W.G. Martin, \& D. Schifter (Eds.), A research companion to Principles and W.G. Martin, \& D. Schifter (Eds.), A research companion to Principles and
Standards for School Mathematics (pp. 27-44). Reston, VA: National Council of Standards for School Mathe
Teachers of Mathematics.

Barbin, E. (2010). Evolving geometric proofs in the seventeenth century: From icons to symbols. In G. Hanna, H.N. Jahnke, \& H. Pulte (Eds.), Explanation and proof in mathematics: Philosophical and educational perspectives (pp. 237-251). New in mathematics: Philosophical and educational perspectives (pp. $237-25$
York, NY: Springer. http://dx.doi.org/10.1007/978-1-4419-0576-5_16

Bell, A.W. (1976). A study of pupils'proof-explanations in mathematical situations. Educational Studies in Mathematics, 7, 23-40. http://dx.doi.org/10.1007/ BF00144356

Borwein, J. (2012). Exploratory experimentation: Digitally-assisted discovery and proof. In G. Hanna, \& M. de Villiers (Eds.), Proof and proving in mathematics education (pp. 69-96). Dordrecht: Springer.

Byers, W. (2007). How mathematicians think. Princeton, NJ: Princeton University Press.

De Villiers, M. (1990). The role and function of proof in mathematics. Pythagoras, 24, 7-24. Available from http://mzone.mweb.co.za/residents/profmd/proofa.pdf

De Villiers, M. (1993). Computer verification vs. algebraic explanation. Pythagoras, 31 , 46. Available from http://mzone.mweb.co.za/residents/profmd/alge.pdf

De Villiers, M. (1998). An alternative approach to proof in dynamic geometry. In R. Lehrer, \& D. Chazan (Eds.), New directions in teaching and learning geometry (pp. 369-415), Mahwah, NJ: Lawrence Erlbaum Associates.

De Villiers, M. (1999). A generalization of an IMTS problem. KwaZulu-Natal AMESA Mathematics Journal, 4(1), 12-15. Available from http://mzone.mweb.co.za/ residents/profmd/imts.pdf

De Villiers, M. (2003). Rethinking proof with Geometer's Sketchpad 4. Emeryville, CA: Key Curriculum Press.

De Villiers, M. (2004). Clough's conjecture: A Sketchpad investigation. In S. Nieuwoudt S. Froneman, \& P. Nkhoma (Eds.), Proceedings of the 10th Annual National Congress of the Association for Mathematics Education of South Africa, Vol. 2 (pp. 52-56). Potchefstroom: AMESA.

De Villiers, M. (2007a). A hexagon result and its generalization via proof. The Montana Mathematics Enthusiast, 4(2), 188-192.

De Villiers, M. (2007b). An example of the discovery function of proof. Mathematics in School, 36(4), 9-11. Available from http://frink.machighway.com/ dynamicm/ crossdiscovery.pdf

Dreyfus, T., Nardi, E., \& Leikin, R. (2012). Forms of proof and proving in the classroom. In G. Hanna, \& M. de Villiers (Eds.), Proof and proving in mathematics education (pp. 191-213). Dordrecht: Springer.

French, D., \& Stripp, C. (Eds.), (reprinted 2005). Are you sure? Learning about proof Leicester: The Mathematical Association.

Grabiner, J.V. (2012). Why Proof? A historian's perspective. In G. Hanna, \& M. de Villiers (Eds.), Proof and proving in mathematics education (pp. 147-168). Dordrecht: Springer.

Hanna, G. (1989). Proofs that prove and proofs that explain. In G. Vergnaud, J. Rogalski, \& M. Artigue (Eds.), Proceedings of the 13th Conference of the International Group for the Psychology of Mathematics Education, Vol. 2 (pp. 45-51). Paris: CNRS.

Hanna, G. (2000). Proof, explanation and exploration: An overview. Educationa Studies in Mathematics, 44, 5-23. http://dx.doi.org/10.1023/A:1012737223465

Hanna, G., \& Barbeau, E. (2010). Proofs as bearers of mathematical knowledge. In G. Hanna, H.N. Jahnke, \& H. Pulte (Eds.), Explanation and proof in mathematics: Philosophical and educational perspectives (pp. 85-100), New York, NY: Springer $\mathrm{http}: / / \mathrm{dx}$.doi.org/10.1007/978-1-4419-0576-5_7

Harel, G., \& Sowder, L. (2007). Towards comprehensive perspectives on the learning and teaching of proof. In F.K. Lester (Ed.), Second handbook of research on mathematics teaching and learning (pp. 805-842). Greenwich, CT: Information Age Publishing.

Healy, L., \& Hoyles, C. (2000). A study of proof conceptions in algebra. Journa for Research in Mathematics Education, 31, 396-428. http://dx.doi. for Research in
org $/ 10.2307 / 749651$

Hemmi, K., \& Löfwall, C. (2011, February). Making discovery function of proof visible for upper secondary school students. Paper presented at CERME 7: Working Group on Argumentation and Proof, Rzeszów, Poland. Available from http://www. cerme7.univ.rzeszow.pl/WG/1/CERME7_WG1_Lofwall.pdf
Hofstadter, D. (1997). Discovery and dissection of a geometric gem. In D. Schattschneider, \& J. King (Eds.). Geometry turned on! (pp. 3-14). Washington, DC: MAA.

Horgan, J. (1993). The death of proof. Scientific American, 269(4), 92-103. http:// dx.doi.org/10.1038/scientificamerican1093-92

Johnston-Wilder, S., \& Mason, J. (Eds.). (2005). Developing thinking in geometry. London: Paul Chapman Publishing.

Jones, K., \& Herbst, P. (2012). Proof, proving, and teacher-student interaction: Theories and contexts. In G. Hanna, \& M. de Villiers (Eds.), Proof and proving in mathematics education (pp. 261-277). Dordrecht: Springer.

Knuth, E.J. (2002). Secondary school mathematics teachers' conceptions of proof. Journal for Research in Mathematics Education, 33(5), 379-405. http://dx.doi. org/10.2307/4149959

Leiken, R. (2011). Teaching the mathematically gifted: Featuring a teacher. Canadian Journal of Science, Mathematics and Technology Education, 11(1), 78-89. http:// dx.doi.org/10.1080/14926156.2011.548902

Leong, Y.H., Toh, T.L., Tay, E.G., Quek, K.S., \& Dindyal, J. (2012). Relooking 'look back': A student's attempt at problem solving using Polya's model. International Journal of Mathematical Education in Science and Technology, 43(3), 357-369. http:// dx.doi.org/10.1080/0020739X.2011.618558

Lin, F., Yang, K., Lee, K., Tabach, M., \& Stylianides, G. (2012). Principles of task design for conjecturing and proving. In G. Hanna, \& M. de Villiers (Eds.), Proof and proving in mathematics education (pp. 305-325). Dordrecht: Springer.

Lockhart, P. (2002) A mathematician's lament. In Devlin's Angle (March 2008) at the Mathematical Association of America website. Available from http://www.maa. org/devlin/LockhartsLament.pdf

Mason, J., Burton, L., \& Stacey, K. (1982). Thinking mathematically. London: AddisonWesley.

Mejía-Ramos, J.P. (2005). Aspects of proof in mathematics. In D. Hewitt (Ed.), Proceedings of the British Society for Research into Learning Mathematics, 25(2).
St. Martin's College, Lancaster: Open University. Available from http://www. St. Martin's College, Lancaster: Open University
bsrlm.org.uk/IPs/ip25-2/BSRLM-IP-25-2-11.pdf

Miyazaki, M. (2000). What are essential to apply the "discovery" function of proof in lower secondary mathematics? In T. Nakahara, \& K. Mastaka (Ed.), Proceedings of the 24th Conference of the International Group for the Psychology of Mathematics the 24th Conference of the International Group for the Psycho
Education, Vol. 4 (pp. 1-8). Hiroshima: Hiroshima University.

Movshovitz-Hadar, N. (1988). School mathematics theorems: An endless source of surprise. For the Learning of Mathematics, 8(3), 34-40.

Mudaly, V., \& De Villiers, M. (2000). Learners' needs for conviction and explanation within the context of dynamic geometry. Pythagoras, 52, 20-23. Available from http://mysite.mweb.co.za/residents/profmd/vim.pdf

Nunokawa, K. (2010). Proof, mathematical problem solving, and explanation in mathematics teaching. In G. Hanna, H.N. Jahnke, \& H. Pulte (Eds.), Explanation and proof in mathematics: Philosophical and educational perspectives ( $\mathrm{pp}$. 223-236). New York, NY: Springer. http://dx.doi.org/10.1007/978-1-4419-0576515

Polya, G. (1945). How to solve it. Princeton, NJ: Princeton University Press.

Polya, G. (1954). Mathematics and plausible reasoning, (Vol. 1). Princeton, NJ: Princeton University Press.

Rav, Y. (1999). Why do we prove theorems? Philosophia Mathematica, 7(3), 5-41. http://dx.doi.org/10.1093/philmat/7.1.5

Reid, D. (2002). What is Proof? International Newsletter on the Teaching and Learning of Mathematical Proof, June 2002. Available from http://www.lettredelapreuve. it/OldPreuve/Newsletter/02Ete/WhatlsProof.pdf

Reid, D. (2011, October). Understanding proof and transforming teaching. Paper presented at the North-American Chapter of the International Group for the Psychology of Mathematics Education, Reno, NV: PME-NA. Available from http:// pmena.org/2011/presentations/PMENA_2011_Reid.pdf

Schoenfeld, A.H. (1987). What's all the fuss about metacognition? In A.H. Schoenfeld (Ed.), Cognitive science and mathematics education (pp. 189-215). Hillsdale, NJ: Lawrence Erlbaum Associates.

Schoenfeld, A.H. (2007). Problem solving in the United States, 1970-2008: Research and theory, practice and politics. ZDM: The International Journal on Mathematics Education, 39, 537-551. http://dx.doi.org/10.1007/s11858-007-0038-z

Stylianides, A.J., \& Ball, D.L. (2008). Understanding and describing mathematical knowledge for teaching: Knowledge about proof for engaging students in the activity of proving. Journal of Mathematics Teacher Education, 11, 307-332. activity of proving. Journal of Mathematics
$\mathrm{http}: / / \mathrm{dx}$.doi.org/10.1007/s10857-008-9077-9

Stylianides, A.J. (2011). Towards a comprehensive knowledge package for teaching proof: A focus on the misconception that empirical arguments are proofs. Pythagoras, 32(1), Art. \#14, 10 pages. http://dx.doi.org/10.4102/pythagoras. Pythagor

Thurston, W.P. (1994). On proof and progress in mathematics. Bulletin of the American Mathematical Society, 30(2), 161-177. http://dx.doi.org/10.1090/S0273-09791994-00502-6

Zack, V. (1997). "You have to prove us wrong": Proof at the elementary school level. In E. Pehkonen (Ed.), Proceedings of the 21st Conference of the International Group for the Psychology of Mathematics Education, Vol. 4 (pp. 291-298). Lahti, Finland: PME. Available from http://meru-urem.ca/articles/Zack1997(PME-Finland).pdf 